\title{
A global assessment of knowledge of dental students about nicotine replacement therapy: findings from 43 countries
}

\author{
I. T. Agaku ${ }^{1}$ and O. A. Ayo-Yusuf ${ }^{1,2}$ \\ ${ }^{1}$ Department of Social and Behavioural Sciences, Centre for Global Tobacco Control, Harvard School of Public Health, Boston, MA, USA, \\ 2 Department of Community Dentistry, University of Pretoria, Pretoria, South Africa
}

\author{
Correspondence \\ Israel T. Agaku \\ Department of Social and Behavioural Sciences Centre for Global Tobacco Control, Harvard School of Public Health, 677 Huntington Avenue, Boston \\ MA 02115, USA \\ Tel: $+1(770) 7283220$ \\ Fax: +1 (770) 4885848 \\ e-mail: iagaku@post.harvard.edu
}

\begin{abstract}
Objectives: Knowledge of nicotine replacement therapy (NRT) is a competency that is expected from receiving training in the treatment for tobacco dependence. This study therefore assessed the knowledge of dental students in 43 countries about NRT.

Methods: The 2005-2011 dental Global Health Professions Student Survey data were analysed for 13,040 third-year dental students from 43 countries. Knowledge about NRT was self-reported and country-specific prevalence estimates were calculated. To assess for correlates of knowledge about NRT amongst dental students, a multivariate logistic regression model was fitted $(P<0.05)$, with pooled data from all 43 countries. The model assessed for geographical location, gross national income, tobacco cessation training in school, sex, current tobacco use and survey year.

Results: Amongst all dental students, the proportion that knew about NRT ranged from 37.0\% (Mongolia) to 97.6\% (Slovakia). The odds of knowing about NRT were lower amongst dental students in the Eastern Mediterranean region $(a \mathrm{OR}=0.52$; 95\%CI: 0.34-0.79) compared to those in the European region. Dental students in upper-middle-income ( $a \mathrm{OR}=2.46$; 95\% CI: $1.57-3.85)$ and high-income countries $(a \mathrm{OR}=4.55$; 95\% CI: 2.28-9.09) both had higher odds of knowing about NRT com-pared to dental students in low-income countries. Also, current use of any tobacco product and receipt of tobacco cessation training in school were both associated with higher likelihood of knowing about NRT. No significant gender differences in knowl-edge of NRT were observed.
\end{abstract}

Conclusions: A large proportion of dental students in several countries knew about NRT. However, disparities in knowledge existed across regions. Enhanced efforts are needed to formally train dental students on tobacco cessation techniques.

keywords

dentists; students; cessation; tobacco; counselling; education.

\section{Introduction}

Tobacco use is the most important modifiable risk factor for several oral conditions including pre-malignancies and frank oral cancer (1-4). Quitting smoking is beneficial to health at any age, and cigarette smokers who quit before age 35 years have mortality rates similar to those who never smoked $(1,5)$. Involvement of healthcare professionals in clinical tobacco cessation interventions has been shown to encourage smokers to make a quit attempt and to stop smoking (6). Such clinical interventions may involve clinical counselling alone or in combination with pharmacologic treatment for nicotine dependence.

Nicotine replacement therapy (NRT) helps to minimise the physical withdrawal symptoms and cravings which smokers may experience at the beginning of a quit attempt by providing the smoker with much less nicotine than a cigarette (7-9). Evidence indicates that pharmacologic treatment of nicotine dependence can double or triple quit rates (10). Most NRT are readily available as over-the-counter medication and include nicotine gum, patch and lozenge. 
Research indicates that only a relatively small fraction of dental students and practicing dentists in several countries have received specific training in tobacco cessation interventions (11-13). This is disturbing because several of the oral conditions dental patients sometimes experience may arise from the use of smokeless or smoked tobacco products. It is thus important for dentists to know how to help their patients to stop tobacco use. One of the key competencies for training in the treatment of tobacco dependence is the knowledge of pharmacotherapy, including NRT (14). More so, the recent inclusion of NRT into the World Health Organisation's (WHO) model list of essential medicines during 2009 makes it imperative for all clinicians to develop knowledge and proficiency regarding best practices for pharmacologic treatment of nicotine dependence (15). Hence, to assess the awareness of dental students about pharmacotherapy for nicotine dependence, this study surveyed third-year dental students in 43 countries about their knowledge about NRT. Nationally representative data were obtained from the 2005-2011 dental Global Health Professions Student Survey (GHPSS).

\section{Methods}

\section{Data source}

The dental GHPSS is an anonymous, self-administered survey that collects information from third-year dental students on tobacco use, exposure to second-hand smoke, desire to quit smoking and training received to provide patient counselling on cessation techniques. The dental GHPSS included a census of both students and schools in all sites, where all eligible schools and students were surveyed - except in the Bolivarian Republic of Venezuela, India and Mexico, where a sample of schools was selected with probability proportional to size from all dental schools in the country and a census of students in the selected schools were surveyed.

\section{Measures}

\section{Self-reported knowledge about NRT}

Self-reported knowledge about NRT was defined as a 'yes' response to the question: 'have you ever heard of nicotine replacement product therapies in tobacco cessation programmes (such as nicotine patch or gum)?'

\section{Education in school on asking about patients' tobacco use status}

Education in school on asking about patients' tobacco use status was defined as a 'yes' response to the question: 'During your dental school training, did you learn that it is important to record tobacco use history as part of a patient's general medical history?'

\section{Education in school on offering assistance to help tobacco users quit}

Education in school on offering assistance to help tobacco users quit was defined as a 'yes' response to the question: 'During your dental school training, did you learn that it is important to provide educational materials to support smoking cessation to patients who want to quit smoking?'

\section{Current use of tobacco products}

Current use of any tobacco product was defined as a report by a student who had smoked manufactured or hand-rolled cigarettes or used any non-cigarette tobacco products (including smoked and smokeless tobacco products such as cigars, pipes, water pipes, chewing tobacco or other tobacco products) on $\geq 1$ day during the past 30 days.

\section{Socio-demographic factors}

Socio-demographic factors assessed included sex (male or female); geographical location and the income group of country.

Geographical location was based on the six WHO regions and included the following regions and countries: the African region ( $n=3$ countries: Algeria, Kenya and Senegal); the Eastern Mediterranean Region $(n=11$ countries: Islamic Republic of Iran, Lebanon, Libyan Arab, Oman, Pakistan, Saudi Arabia, Sudan, Syrian Arab Republic, Tunisia, and Yemen); the European region ( $n=10$ countries: Albania, Armenia, Bosnia \& Herzegovina, Bulgaria, Czech Republic, Lithuania, Russian Federation, Serbia, Slovenia, and Slovakia); the region of the Americas $(n=10$ countries: Argentina, Bolivarian Republic of Venezuela, Bolivia, Chile, Guatemala, Mexico, Panama, Paraguay, Trinidad \& Tobago, and Uruguay); the South-East Asian region ( $n=7$ countries: Bangladesh, India, Indonesia, Myanmar, Nepal, Sri Lanka and Thailand); and the Western Pacific region ( $n=2$ countries: Cambodia and Mongolia).

The categorisation of countries into income groups in this study followed the World Bank classification (16) and was based on the countries' Gross National Income or GNI during the corresponding survey year. Based on this criterion, income categories included the following: low-income $(n=5$ countries: Bangladesh, Cambodia, Kenya, Myanmar, and Nepal); lowermiddle income $(n=19$ countries: Albania, Algeria, Armenia, Bolivia, Bosnia \& Herzegovina, Guatemala, India, Indonesia, Islamic Republic of Iran, Mongolia, Morocco, Pakistan, Paraguay, Senegal, Sri Lanka, Sudan, Syrian Arab Republic, Tunisia, and Yemen); upper-middle income ( $n=14$ countries: Argentina, Bolivarian Republic of Venezuela, Bulgaria, Chile, Lebanon, Libyan Arab, Lithuania, Mexico, Panama, Russian Federation, Serbia, Slovakia, Thailand, and Uruguay) and highincome countries ( $n=5$ countries: Czech Republic, Oman, Saudi Arabia, Slovenia, and Trinidad \& Tobago).

\section{Analysis}

Data from each country were weighted to account for the complex survey design. Overall and sex-specific prevalence estimates of knowledge about NRT amongst dental students were calculated for each country and compared using chi-square statistics. For all countries where a complete census of dental schools and dental students were taken (i.e. all sites excluding Bolivarian Republic of Venezuela, India and Mexico), a finite population 
correction factor was applied to take into account non-response and used in the variance of the estimates.

To assess for correlates of knowledge about NRT amongst dental students, a multivariate logistic regression model was fitted with pooled data from all 43 countries. The model adjusted for geographical location, gross national income, tobacco cessation training in school, sex, current tobacco use, and survey year. All statistical tests were two-tailed and the level of statistical significance was set at $P<0.05$. Data analyses were performed with Stata 11 (StataCorp 2009, TX), and results are presented by WHO region.

\section{Results}

\section{Characteristics of study participants}

In total, this study analysed data for 13,040 third-year dental students from 43 countries during 2005-2011. About 95\% or more of all dental students were younger than 30 years old. The proportion of female dental students ranged from $22.7 \%$ in Myanmar to $87.2 \%$ in Slovenia. The number of dental students who completed the survey in each country ranged from 18 students in one dental school (Trinidad \& Tobago) to 1, 658 students in 17 dental schools (Bolivia). Other characteristics of the study population are shown in Table 1 .

\section{Prevalence of self-reported knowledge about NRT}

Amongst all dental students, the proportion that knew about NRT ranged from $37.0 \%$ in Mongolia to $97.6 \%$ in Slovakia. In the African region, prevalence ranged from $44.4 \%$ in Senegal to $79.2 \%$ in Kenya. In the Eastern Mediterranean region, prevalence ranged from $51.6 \%$ in Tunisia to $81.9 \%$ in Lebanon. In the European region, prevalence ranged from 51.8 in Armenia to $97.6 \%$ in Slovakia. In the region of the Americas, prevalence ranged from $51.1 \%$ in Bolivia to $97.0 \%$ in Guatemala. Prevalence in the South-East Asian region ranged from 50.4\% in Myanmar to $86.2 \%$ in Nepal. In the Western Pacific region, prevalence rates in Mongolia and Cambodia were $37.0 \%$ and $43.5 \%$, respectively (Table 2 ).

\section{Factors associated with knowledge about NRT}

After adjusting for potential confounders, knowledge about NRT was significantly associated with geographical and income group of country, receipt of tobacco cessation training in school, and current tobacco use status of dental students. By geographical region, the odds of knowing about NRT were significantly lower amongst dental students in the Eastern Mediterranean $(a \mathrm{OR}=0.52 ; 95 \%$ CI: $0.34-0.79)$, the Americas $(a \mathrm{OR}=0.50 ; \quad 95 \% \quad$ CI: $0.39-0.63), \quad$ South East Asia $(a \mathrm{OR}=0.51 ; \quad 95 \% \quad \mathrm{CI}: \quad 0.35-0.74), \quad$ and Western Pacific $(a \mathrm{OR}=0.18 ; 95 \% \mathrm{CI}: 0.11-0.31)$ regions compared to those in the European region. No significant differences were noted between dental students in the African region when compared to the European region (Table 3).

On stratifying by income group of country, a significant gradient was observed, with the likelihood of knowing about
NRT rising with increasing gross national income of country. Dental students in upper-middle-income $(a \mathrm{OR}=2.46 ; 95 \%$ CI: $1.57-3.85)$ and high-income countries $(a \mathrm{OR}=4.55 ; 95 \%$ CI: 2.28-9.09) both had significantly higher odds of knowing about NRT compared to dental students in low-income countries. Dental students from lower-middle-income countries had higher odds of knowing about NRT compared to those from low-income countries although this difference did not attain statistical significance $(a \mathrm{OR}=1.26 ; 95 \% \mathrm{CI}$ : 0.85-1.87).

In addition, being taught about the importance of asking about patients' tobacco use status $(a \mathrm{OR}=1.87$; 95\% CI: $1.54-$ 2.26), as well as the importance of offering assistance to help smokers quit $(a \mathrm{OR}=1.68 ; 95 \% \mathrm{CI}: 1.40-2.02)$, both significantly increased the likelihood of knowing about NRT. Furthermore, being a current user of any tobacco product $(a \mathrm{OR}=1.32 ; 95 \% \mathrm{CI}: 1.15-1.51)$ conferred significantly higher odds of knowing about NRT. Knowledge about NRT did not vary significantly by sex.

\section{Discussion}

This study indicated that knowledge about NRT was generally high amongst dental students in most countries. In 18 of 43 countries surveyed, over $75 \%$ of dental students knew about NRT. However, significant disparities were observed amongst some populations. For example, by geographical location, the likelihood of knowing about NRT was significantly higher amongst dental students in the European region compared to most other regions, which may be due to regional differences in prevalence and intensity of cigarette smoking (10). Low awareness of NRT amongst health profession students in countries with low smoking prevalence or intensity may be because NRT might not be indicated in most instances for the treatment of tobacco use in these countries.

Similarly, by income group, the likelihood of knowing about NRT was lowest amongst students in low-income countries and highest amongst students in high-income countries, which may be due to stronger national tobacco control programmes in more affluent countries. Smoking cessation programmes are primarily the responsibility of each country's healthcare system and are most effective when they are part of a coordinated and well-funded tobacco control programme (10). Unlike some low- and middle-income countries, high-income countries may have the resources to offer a wide range of free cessation services as part of their comprehensive tobacco control programmes, including free access to pharmacotherapy for nicotine dependence for all smokers that visit healthcare centres. Hence, dental students in such countries may have several exposures to clinical cessation interventions over the course of their dental training. This is well illustrated with New Zealand, where tobacco cessation intervention is one of the national government's top priorities, and where the healthcare system follows an ' $A B C$ ' model; Ask smoking status, give Brief advice, and offer Cessation support (10). The United Kingdom National Health Service also provides cessation support to all smokers who are ready to quit (17). The global disparities in access to clinical tobacco cessation interventions are highlighted by the WHO's 2011 report on the global tobacco epidemic, 
TABLE 1. Characteristics of Surveyed Dental Students in 43 Countries, Global Health Professions Student Survey, 2005-2011 ( $n=13,40)$

\begin{tabular}{|c|c|c|c|c|c|c|c|}
\hline Region/Country & $\begin{array}{l}\text { Income category of } \\
\text { country during } \\
\text { survey year }\end{array}$ & Survey year & $\begin{array}{l}\text { Number } \\
\text { of respondents }\end{array}$ & $\begin{array}{l}\text { Number of } \\
\text { dental schools }{ }^{1}\end{array}$ & $\begin{array}{l}\text { overall response } \\
\text { rate }\end{array}$ & $\%$ females & $\begin{array}{l}\% \text { aged } \\
<30 \text { years }\end{array}$ \\
\hline \multicolumn{8}{|l|}{ African region } \\
\hline Algeria & Lower-middle & 2007 & 225 & 2 & 76.7 & 62.5 & 99.3 \\
\hline Kenya & low & 2008 & 24 & 1 & 86.2 & 50.0 & 100.0 \\
\hline Senegal & Lower-middle & 2009 & 36 & 1 & 74.0 & 52.8 & 100.0 \\
\hline \multicolumn{8}{|c|}{ Eastern Mediterranean region } \\
\hline Islamic Republic of Iran & Lower-middle & 2007 & 303 & 15 & 58.7 & 53.7 & 96.6 \\
\hline Lebanon & Upper-middle & 2006 & 71 & 3 & 64.0 & 67.2 & 100.0 \\
\hline Libyan Arab & Upper-middle & 2006 & 162 & 8 & 39.1 & 71.8 & 100.0 \\
\hline Sudan & Lower-middle & 2007 & 135 & 6 & 56.3 & 61.3 & 100.0 \\
\hline Syrian Arab Republic & Lower-middle & 2006 & 475 & 4 & 86.2 & 38.2 & 99.3 \\
\hline Tunisia & Lower-middle & 2007 & 123 & 1 & 62.4 & 79.5 & 100.0 \\
\hline Morocco & Lower-middle & 2010 & 119 & 2 & 87.1 & 74.7 & 100.0 \\
\hline Saudi Arabia & High & 2010 & 73 & 5 & 83.1 & 43.3 & 97.4 \\
\hline Oman & High & 2010 & 52 & 1 & 86.7 & 87.0 & 100.0 \\
\hline Pakistan & Lower-middle & 2011 & 400 & 8 & 70.3 & 62.4 & 98.2 \\
\hline Yemen & Lower-middle & 2009 & 389 & 6 & 84.0 & 64.3 & 99.8 \\
\hline \multicolumn{8}{|l|}{ European region } \\
\hline Albania & Lower-middle & 2011 & 224 & 4 & 84.8 & 56.7 & 97.9 \\
\hline Armenia & Lower-middle & 2006 & 149 & 3 & 62.7 & 58.7 & 100.0 \\
\hline Bosnia \& Herzegovina & Lower-middle & 2006 & 170 & 3 & 94.4 & 66.9 & 100.0 \\
\hline Czech Republic & High & 2011 & 187 & 4 & 81.3 & 65.8 & 98.9 \\
\hline Lithuania & Upper-middle & 2006 & 72 & 2 & 64.3 & 82.6 & 100.0 \\
\hline Russian Federation & Upper-middle & 2006 & 583 & 5 & 80.0 & 63.2 & 100.0 \\
\hline Serbia & Upper-middle & 2006 & 212 & 3 & 73.7 & 41.5 & 99.0 \\
\hline Slovakia & Upper-middle & 2006 & 42 & 2 & 100.0 & 66.7 & 100.0 \\
\hline Slovenia & High & 2007 & 39 & 1 & 100.0 & 87.2 & 100.0 \\
\hline Bulgaria & Upper-middle & 2009 & 193 & 3 & 93.8 & 59.4 & 96.4 \\
\hline \multicolumn{8}{|l|}{ Region of the Americas } \\
\hline Argentina & Upper-middle & 2007 & 237 & 4 & 95.7 & 67.2 & 96.6 \\
\hline Bolivia & Lower-middle & 2007 & 1,658 & 17 & 91.8 & 59.8 & 95.4 \\
\hline Chile & Upper-middle & 2008 & 792 & 22 & 72.2 & 55.3 & 97.6 \\
\hline Guatemala & Lower-middle & 2008 & 99 & 3 & 86.4 & 76.1 & 95.9 \\
\hline Mexico & Upper-middle & 2006 & 1,301 & 15 & 74.1 & 68.3 & 98.9 \\
\hline Paraguay & Lower-middle & 2008 & 147 & 7 & 65.7 & 75.6 & 98.0 \\
\hline Trinidad \& Tobago & High & 2008 & 18 & 1 & 66.7 & 55.6 & 100.0 \\
\hline Uruguay & Upper-middle & 2008 & 95 & 2 & 94.3 & 73.7 & 94.7 \\
\hline Panama & Upper-middle & 2008 & 57 & 2 & 86.1 & 68.3 & 100.0 \\
\hline $\begin{array}{l}\text { Venezuela, Bolivarian } \\
\text { Republic of National }\end{array}$ & Upper-middle & 2011 & 1233 & 4 & 86.0 & 82.4 & 98.8 \\
\hline \multicolumn{8}{|l|}{ South East Asia region } \\
\hline Bangladesh & Low & 2009 & 337 & 9 & 86.0 & 59.8 & 98.8 \\
\hline India & Lower-middle & 2009 & 711 & 15 & 83.6 & 67.6 & 99.8 \\
\hline Indonesia & Lower-middle & 2007 & 753 & 9 & 89.5 & 82.3 & 99.9 \\
\hline Myanmar & Low & 2009 & 260 & 2 & 75.7 & 22.7 & 98.8 \\
\hline Nepal & Low & 2011 & 73 & 4 & 83.9 & 45.1 & 100.0 \\
\hline Thailand & Upper-middle & 2011 & 566 & 8 & 84.6 & 68.7 & 100.0 \\
\hline Sri Lanka & Lower-middle & 2011 & 59 & 1 & 86.6 & 74.1 & 100.0 \\
\hline \multicolumn{8}{|l|}{ Western Pacific region } \\
\hline Cambodia & Low & 2005 & 47 & 1 & 85.5 & 43.5 & 100.0 \\
\hline Mongolia & Lower-middle & 2007 & 139 & 2 & 100.0 & 75.0 & 99.3 \\
\hline
\end{tabular}

Numbers of respondents were unweighted whilst percentages were weighted to account for the complex survey design.

${ }^{1}$ Complete census of all dental schools in the country, except for Bolivarian Republic of Venezuela, India and Mexico where a sample of dental schools was taken. 
TABLE 2. Prevalence of Self-Reported Knowledge About Nicotine Replacement Therapy Amongst Dental Students in 43 Countries, Overall and by Sex, Global Health Professions Student Survey, 2005-2011 $(\mathrm{n}=13,040)$

\begin{tabular}{|c|c|c|c|c|}
\hline Region/Country & Survey year & Overall\% $(95 \% \mathrm{CI})$ & Females\% $(95 \% \mathrm{Cl})$ & Males\% $(95 \% \mathrm{Cl})$ \\
\hline \multicolumn{5}{|l|}{ African region } \\
\hline Algeria $(n=225)$ & 2007 & $64.0(43.5-84.5)$ & $68.3(44.2-92.3)$ & $57.4(45.0-69.8)$ \\
\hline Kenya $(n=24)$ & 2008 & $79.2(79.2-79.2)$ & $75.0(75.0-75.0)$ & $83.3(83.3-83.3)$ \\
\hline Senegal $(n=36)$ & 2009 & $44.4(44.4-44.4)$ & $31.6(-)$ & $58.8(58.8-58.8)$ \\
\hline \multicolumn{5}{|l|}{ Eastern Mediterranean region } \\
\hline Islamic Republic of Iran $(n=303)$ & 2007 & $69.7(59.0-80.3)$ & $67.9(55.4-80.4)$ & $72.3(61.7-82.9)$ \\
\hline Lebanon $(n=71)$ & 2006 & $81.9(74.5-89.4)$ & $84.1(68.2-100.0)$ & $77.6(63.5-91.6)$ \\
\hline Libyan Arab $(n=162)$ & 2006 & $56.3(50.4-62.2)$ & $58.8(51.2-66.4)$ & $50.8(46.1-55.6)$ \\
\hline Sudan $(n=135)$ & 2007 & $73.5(65.7-81.3)$ & $75.4(66.7-84.1)$ & $70.3(58.6-82.0)$ \\
\hline Syrian Arab Republic $(n=475)$ & 2006 & $58.2(51.3-65.1)$ & $58.8(48.3-69.4)$ & $57.8(49.7-66.0)$ \\
\hline Tunisia $(n=123)$ & 2007 & $51.6(51.6-51.6)$ & $55.2(55.2-55.2)$ & $36.0(36.0-36.0)$ \\
\hline $\operatorname{Morocco}(n=119)$ & 2010 & $65.4(63.0-67.7)$ & $69.2(63.3-75.1)$ & $56.5(42.4-70.7)$ \\
\hline Saudi Arabia $(n=73)$ & 2010 & $81.8(75.0-88.5)$ & $82.9(70.6-95.2)$ & $80.5(75.7-85.3)$ \\
\hline Oman $(n=52)$ & 2010 & $55.1(55.1-55.1)$ & $52.5(52.5-52.5)$ & $50.0(-)$ \\
\hline Pakistan $(n=400)$ & 2011 & $61.4(46.3-76.5)$ & $58.2(37.1-79.4)$ & $66.6(56.3-76.9)$ \\
\hline Yemen $(n=389)$ & 2009 & $64.4(62.2-66.6)$ & $67.0(59.9-74.1)$ & $59.9(50.2-69.6)$ \\
\hline \multicolumn{5}{|l|}{ European region } \\
\hline Albania $(n=224)$ & 2011 & $73.6(68.8-78.4)$ & $71.1(63.4-78.8)$ & $76.8(76.2-77.4)$ \\
\hline Armenia $(n=149)$ & 2006 & $51.8(39.1-64.5)$ & $52.0(27.7-76.3)$ & $49.8(35.1-64.5)$ \\
\hline Bosnia \& Herzegovina $(n=170)$ & 2006 & $85.2(80.7-89.6)$ & $84.1(75.7-92.5)$ & $87.3(83.2-91.4)$ \\
\hline Czech Republic $(n=187)$ & 2011 & $94.1(91.0-97.2)$ & $95.1(91.9-98.2)$ & $92.3(88.1-96.5)$ \\
\hline Lithuania $(n=72)$ & 2006 & $76.0(59.0-93.1)$ & $76.4(61.4-91.4)$ & $74.1(46.4-100.0)$ \\
\hline Russian Federation $(n=583)$ & 2006 & $88.5(85.5-91.5)$ & $90.1(86.3-93.9)$ & $85.4(83.2-87.7)$ \\
\hline Serbia $(n=212)$ & 2006 & $86.2(83.0-89.3)$ & $81.0(68.2-93.9)$ & $89.4(87.0-91.8)$ \\
\hline Slovakia $(n=42)$ & 2006 & $97.6(92.6-100.0)$ & $100.0(-)$ & $92.9(76.6-100.0)$ \\
\hline Slovenia $(n=39)$ & 2007 & $97.4(97.4-97.4)$ & $97.1(97.1-97.1)$ & $100.0(-)$ \\
\hline Bulgaria $(n=193)$ & 2009 & $95.6(92.0-99.3)$ & $96.3(92.5-100.0)$ & $94.6(87.1-100.0)$ \\
\hline \multicolumn{5}{|l|}{ Region of the Americas } \\
\hline Argentina $(n=237)$ & 2007 & $65.4(62.4-68.5)$ & $70.3(67.9-72.7)$ & $55.9(45.6-66.3)$ \\
\hline Bolivia $(n=1658)$ & 2007 & $51.1(48.1-54.1)$ & $50.7(45.6-55.7)$ & $51.7(49.5-54.0)$ \\
\hline Chile $(n=792)$ & 2008 & $85.0(83.0-87.1)$ & $82.2(78.5-85.9)$ & $88.5(86.2-90.8)$ \\
\hline Guatemala $(n=99)$ & 2008 & $97.0(96.6-97.3)$ & $96.0(95.3-96.7)$ & $100.0(-)$ \\
\hline $\operatorname{Mexico}(n=1301)$ & 2006 & $82.4(78.9-86.0)$ & $83.0(79.3-86.6)$ & $81.3(77.2-85.4)$ \\
\hline Paraguay $(n=147)$ & 2008 & $60.4(50.5-70.3)$ & $60.0(56.7-63.4)$ & $61.7(31.3-92.1)$ \\
\hline Trinidad \& Tobago $(n=18)$ & 2008 & $94.4(94.4-94.4)$ & $90.0(90.0-90.0)$ & $100.0(-)$ \\
\hline Uruguay $(n=95)$ & 2008 & $90.5(87.6-93.5)$ & $88.6(86.5-90.7)$ & $96.0(92.2-99.8)$ \\
\hline Panama $(n=57)$ & 2008 & $77.1(70.5-83.7)$ & $74.3(68.7-79.9)$ & $83.2(72.5-93.9)$ \\
\hline $\begin{array}{l}\text { Venezuela, Bolivarian Republic } \\
\text { of, National }(n=1233)\end{array}$ & 2011 & $68.9(64.9-72.8)$ & $70.3(65.6-75.1)$ & $63.2(60.8-65.6)$ \\
\hline \multicolumn{5}{|l|}{ South East Asian region } \\
\hline Bangladesh $(n=337)$ & 2009 & $47.4(35.2-59.6)$ & $46.7(34.1-59.3)$ & $48.5(35.7-61.3)$ \\
\hline India $(n=711)$ & 2009 & $62.9(57.2-68.7)$ & $65.4(58.7-72.1)$ & $57.4(47.3-67.5)$ \\
\hline Indonesia $(n=753)$ & 2007 & $69.3(65.9-72.6)$ & $69.5(65.0-74.0)$ & $69.4(61.5-77.3)$ \\
\hline Myanmar $(n=260)$ & 2009 & $50.4(31.9-68.9)$ & $41.0(24.7-57.4)$ & $53.1(34.2-72.0)$ \\
\hline Nepal $(n=73)$ & 2011 & $86.2(83.5-88.8)$ & $78.6(74.6-82.6)$ & $92.8(87.6-98.0)$ \\
\hline Thailand $(n=566)$ & 2011 & $72.2(63.6-80.9)$ & $71.9(65.4-78.5)$ & $72.2(56.7-87.7)$ \\
\hline Sri Lanka $(n=59)$ & 2011 & $74.6(74.6-74.6)$ & $76.7(76.7-76.7)$ & $66.7(66.7-66.7)$ \\
\hline \multicolumn{5}{|l|}{ Western Pacific region } \\
\hline Cambodia $(n=47)$ & 2005 & $43.5(43.5-43.5)$ & $28.0(28.0-28.0)$ & $65.0(-)$ \\
\hline Mongolia $(n=139)$ & 2007 & $37.0(21.9-52.1)$ & $34.3(23.8-44.7)$ & $45.5(20.1-70.8)$ \\
\hline
\end{tabular}

Some $95 \%$ confidence intervals $(95 \% \mathrm{Cl}$ ) may not be present, or when shown may not vary from the point estimate because a complete census of all dental schools and all dental students in the country was taken. All data were weighted to account for the complex survey design.

which indicated that $80 \%$ of high-income countries provide at least some cost coverage for tobacco dependence, compared to only about $40 \%$ of middle-income countries and $0 \%$ of low-income countries (10). This underscores the need for developing countries to strengthen their national tobacco control programmes and their healthcare system to provide clinical 
TABLE 3. Pooled Multivariate ${ }^{1}$ Logistic Regression Analyses Assessing Correlates of Knowledge About Nicotine Replacement Therapy Amongst Dental Students in 43 Countries, Global Health Professions Student Survey, 2005-2011 ( $\mathrm{n}=13,040)$

\begin{tabular}{|c|c|c|}
\hline Characteristic & $\begin{array}{l}\text { Unadjusted odds } \\
\text { ratios ( } 95 \% \mathrm{CI})\end{array}$ & $\begin{array}{l}\text { Adjusted odds } \\
\text { ratios }(95 \% \mathrm{Cl})\end{array}$ \\
\hline \multicolumn{3}{|l|}{ Country Classification } \\
\hline \multicolumn{3}{|l|}{ WHO geographical region } \\
\hline European region & $1.00^{\text {ref }}$ & $1.00^{\text {ref }}$ \\
\hline African region & $0.33(0.15-0.74)$ & $0.69(0.31-1.57)$ \\
\hline $\begin{array}{l}\text { Eastern Mediterranean } \\
\text { region }\end{array}$ & $0.33(0.26-0.43)$ & $0.52(0.34-0.79)$ \\
\hline Region of the Americas & $0.52(0.42-0.64)$ & $0.50(0.39-0.63)$ \\
\hline South East Asian region & $0.35(0.27-0.45)$ & $0.51(0.35-0.74$ \\
\hline Western Pacific region & $0.13(0.07-0.22)$ & $0.18(0.11-0.31)$ \\
\hline \multicolumn{3}{|l|}{ World Bank Income group } \\
\hline Low-income & $1.00^{\text {ref }}$ & $1.00^{\text {ref }}$ \\
\hline Lower-Middle income & $1.41(0.94-2.12)$ & $1.26(0.85-1.87)$ \\
\hline Upper-Middle income & $2.93(1.98-4.33)$ & $2.46(1.57-3.85)$ \\
\hline High income & $5.81(2.63-12.82)$ & $4.55(2.28-9.09)$ \\
\hline \multicolumn{3}{|c|}{ Tobacco cessation training in dental school } \\
\hline \multicolumn{3}{|c|}{ Taught to ask about patients' tobacco use } \\
\hline No & $1.00^{\text {ref }}$ & $1.00^{\text {ref }}$ \\
\hline Yes & $2.18(1.77-2.69)$ & $1.87(1.54-2.26)$ \\
\hline \multicolumn{3}{|l|}{ Taught to assist smokers to quit } \\
\hline No & $1.00^{\text {ref }}$ & $1.00^{\text {ref }}$ \\
\hline Yes & $1.56(1.32-1.84)$ & $1.68(1.40-2.02)$ \\
\hline \multicolumn{3}{|c|}{ Tobacco use and socio-demographic characteristics } \\
\hline \multicolumn{3}{|c|}{ Current any tobacco user ${ }^{2}$} \\
\hline No & $1.00^{\text {ref }}$ & $1.00^{\text {ref }}$ \\
\hline Yes & $1.38(1.24-1.54)$ & $1.32(1.15-1.51)$ \\
\hline \multicolumn{3}{|l|}{ Sex } \\
\hline Female & $1.00^{\text {ref }}$ & $1.00^{\text {ref }}$ \\
\hline Male & $0.88(0.74-1.04)$ & $0.92(0.77-1.09)$ \\
\hline Survey year (per unit increase) & $0.96(0.92-1.00)$ & $0.94(0.90-0.99)$ \\
\hline
\end{tabular}

$\mathrm{Cl}$, confidence interval; ref, referent category.

All data were weighted to account for the complex survey design.

${ }^{1}$ Adjusted for all factors listed in table.

${ }^{2}$ Defined as use of at least one of the following tobacco products on $\geq 1$ day during the past 30 days: manufactured or hand rolled cigarettes, cigars, pipes, water pipes or smokeless tobacco products (e.g. chewing tobacco).

cessation interventions to help smokers quit. The dental setting has been suggested as an ideal setting to provide such cessation support (18).

Mere knowledge about NRT or simply having heard about NRT - as was assessed in the study - is not a guarantee of proficiency in use of NRT to assist smokers to quit. However, the lack thereof is a strong indicator of lack of competency in the pharmacologic treatment of nicotine dependence. Our study indicated that in some countries, less than half of dental students had ever heard of NRT. This may be because primary health physicians have been the main focus for tobacco cessation in several countries. More so, evidence from several countries indicates that dentists are less active than other health professionals in counselling patients on tobacco cessation (12, 13, 19). However, dentists are well suited to help their patients to quit tobacco use because of several factors. First, it may be relatively easier for dentists to readily detect oral or peri-oral signs or symptoms of tobacco use during oral examinations. This is important because some patients (particularly adolescents) who use tobacco may be unwilling to disclose their tobacco use status because of perceived social undesirability of tobacco use (20). In addition, the relatively long duration of some dental consultations, such as for scaling and polishing, may provide excellent opportunities to engage patients in tobacco cessation intervention. Furthermore, dental patients with tobacco-attributable conditions such as acute necrotising ulcerative gingivitis, or oral cancer, have unique challenges such as difficulties in eating, chewing, drinking, breathing, speaking, as well as aesthetic challenges, which may have a negative impact on quality of life (21). The emotional trauma associated with such conditions may tend to make dental patients comply with recommended therapy. Finally, because of the expensive and time-intensive nature of some dental treatments such as root canal therapy, dental implants, crown/bridgework and orthodontic treatment, coupled with the adverse effect which smoking may have on the success of such treatment, it may be easier for dentists to convince their patients to quit smoking on the basis of both the overall oral and systemic health benefits of quitting, as well as the economic benefits (i.e., averted costs from failed dental treatment secondary to smoking). Such advice to quit smoking may be accompanied by pharmacologic treatment for nicotine dependence.

The fact that knowledge of NRT was associated with being taught to ask about patients' tobacco use status and offer assistance to help smokers quit underscores the need for dental schools to incorporate tobacco cessation training as an integral part of dental education. In line with the guidelines of Article 12 of the WHO's Framework Convention on Tobacco Control (22) and the U.S. Public Health Service Clinical Practice Guideline for treating tobacco use and dependence (23), dental students should be taught to regularly implement the recommended five step approach to help smokers quit, also known as '5 A's' which includes the following: Asking all patients whether they use tobacco; Advising all smokers to quit; Assessing smokers' willingness to quit; Assisting smokers with quitting (including the use of pharmacotherapy); and Arranging follow-up contact to prevent relapse.

To enhance the self-efficacy of practicing dentists in implementing tobacco cessation intervention, education through continuing medical education, seminars and workshops may be necessary. However, such training may be most beneficial if inculcated into dental students early during their professional training. This may be achieved by integrating tobacco cessation training as a core component of the training of dental students (19). Dental classes such as pharmacology, oral medicine and community dentistry/dental public health may be modified to include modules on pharmacologic treatment of tobacco dependence. Such training should be based on the best practices for nicotine dependence treatment and emphasise clinically relevant information such as indications and contraindications, dosage/ duration of use, and patient instructions for use of NRT. In addition, because treatment dose is dependent on level of nicotine addiction, it is important for dental students to be taught how to assess for nicotine dependence. 
The fact that being a tobacco user was associated with knowledge of NRT is not surprising and may be due to past use of NRT by dental students who currently use tobacco. Health profession students who use any products should be encouraged to quit because it is possible for patients to view them as role models $(12,13)$. More so, health professionals who use tobacco products may be less inclined to assist smokers to quit. Hospital administrators can also enact policies to make all hospital environment $100 \%$ smoke-free so as to encourage health professionals including dental and other health profession students to quit.

The findings in this report are subject to some limitations. First, knowledge about NRT was self-reported and may have resulted in recall bias. Second, the GHPSS surveyed third-year students, so it is possible that students received training on patient cessation techniques during the latter (e.g. clinical) years of their programmes. However, to assess whether this was the case in the countries surveyed, the GHPSS research coordinators from each country raised this question to school administrators or others with knowledge of curricula for didactic training of health profession students following the completion of the survey and found that in over $80 \%$ of countries assessed, there was no formal training received by students on tobacco cessation at any time during their training (19). Thus, the results found in this study may be reflective of both pre-clinical and clinical dental students in the majority of countries assessed. However, it must be noted that because these students may have had relatively little interaction with patients whilst in dental school, these results may not be generalisable to practicing clinicians in any of the countries. Finally, because there were limited countries for which data were available these findings may not be generalisable to the respective regions. For example, the surveyed countries in the European region were mainly former Eastern-European and Balkanic countries, whose dental education may be different from Scandinavian or other European countries.

\section{Conclusion}

This study showed that a large proportion of dental students in several countries know about NRT. However, disparities in knowledge existed by geographical location, gross national income, age and tobacco use status. Enhanced and sustained efforts are needed to integrate tobacco cessation training as a core component of the training of dental students through classes.

\section{Acknowledgements}

Dr. Israel Agaku initiated the reported research whilst affiliated with the Centre for Global Tobacco Control at Harvard University. He is currently affiliated with the United States Centres for Disease Control and Prevention's Office on Smoking and Health. The research in this report was completed and submitted outside of the official duties of his current position and does not reflect the official policies or positions of the Centres for Disease Control and Prevention.

\section{Funding}

There was no source of direct or indirect funding for the reported research.

\section{Conflict of interest}

The authors have no competing interests to report.

\section{References}

1 U.S. Department of Health and Human Services. How tobacco smoke causes disease: the biology and behavioral basis for smokingattributable disease: a report of the surgeon general. Atlanta, GA: US Department of Health and Human Services, CDC, 2010. Available at http://www.cdc.gov/tobacco/data_statistics/sgr/2010/ index.htm. Accessed December 10, 2012.

2 Greer RO Jr. Oral manifestations of smokeless tobacco use. Otolaryngol Clin North Am 2011: 44: 31-56.

3 Bunnell A, Pettit N, Reddout N, et al. Analysis of primary risk factors for oral cancer from select US states with increasing rates. Tob Induc Dis 2010: 8: 5.

4 Warnakulasuriya S, Dietrich T, Bornstein MM, et al. Oral health risks of tobacco use and effects of cessation. Int Dent J 2010: 60: 7-30.

5 Doll R, Peto R, Boreham J, Sutherland I. Mortality in relation to smoking: 50 years' observations on male British doctors. BMJ 2004: 328: 1519.

6 Patnode CD, O’Connor E, Whitlock EP, Perdue LA, Soh C, Hollis J. Primary care-relevant interventions for tobacco use prevention and cessation in children and adolescents: a systematic evidence review for the U.S. preventive services task force. Ann Intern Med 2013: 158: 253-260.

7 Silagy C, Mant D, Fowler G, Lancaster T. Nicotine replacement therapy for smoking cessation. Cochrane Database Syst Rev 2000: CD000146.

8 Ashare RL, Wileyto EP, Perkins KA, Schnoll RA. The first 7 days of a quit attempt predicts relapse: validation of a measure for screening medications for nicotine dependence. J Addict Med 2013: 7: 249-254.

9 Westman EC, Behm FM, Simel DL, Rose JE. Smoking behavior on the first day of a quit attempt predicts long-term abstinence. Arch Intern Med 1997: 157: 335-340.

10 World Health Organization. WHO Report on the Global Tobacco Epidemic, 2011. Warning about the dangers of tobacco. Available at http://www.who.int/tobacco/global_report/2011/en/. Accessed May 23, 2013.

$11 \mathrm{Hu}$ S, Pallonen U, McAlister AL, et al. Knowing how to help tobacco users. Dentists' familiarity and compliance with the clinical practice guideline. J Am Dent Assoc 2006: 137: 170-179.

12 Tomar SL. Dentistry's role in tobacco control. J Am Dent Assoc 2001: 132(Suppl): 30S-35S.

13 Warren CW, Sinha DN, Lee J, Lea V, Jones N, Asma S. Tobacco use, exposure to secondhand smoke, and cessation counseling training of dental students around the world. J Dent Educ 2011: 75: 385-405.

14 Association for the Treatment of Tobacco Use and Dependence. Council for Tobacco Treatment Training Programs. Accreditation for Tobacco Treatment Specialist (TTS) Training Programs. Available at http://attudaccred.org/. Accessed June 16, 2013.

15 World Health Organization. WHO Model Lists of Essential Medicines, 2013. Available at http://www.who.int/medicines/ publications/essentialmedicines/en/index.html. Accessed July 28, 2013 
16 The World Bank. Country and Lending Groups. Available at http:// data.worldbank.org/about/country-classifications/ country-and-lending-groups. Accessed May 12, 2013.

17 NHS. National Institute for Health and Clinical Excellence. Smoking Cessation Services in Primary Care, Pharmacies, Local Authorities and Workplaces, Particularly for Manual Working Groups, Pregnant Women and Hard to Reach Communities. 2008. Available at www.nice.org.uk/PH010. Accessed May 31, 2013

18 Gordon JS, Severson HH. Tobacco cessation through dental office settings. J Dent Educ 2001: 65: 354-363.

19 Warren CW, Jones NR, Chauvin J, Peruga A, GTSS Collaborative Group. Tobacco use and cessation counselling: cross-country. Data from the Global Health Professions Student Survey (GHPSS), 20057. Tob Control 2008: 17: 238-247.
20 Hennrikus D, Rindal DB, Boyle RG, Stafne E, Lazovich D, Lando H. How well does the health history form identify adolescent smokers? J Am Dent Assoc 2005: 136: 11131120.

21 Koster ME, Bergsma J. Problems and coping behaviour of facial cancer patients. Soc Sci Med 1990: 30: 569-578.

22 World Health Organization (2003). WHO Framework Convention on Tobacco Control. Available at http://whqlibdoc. who.int/publications/2003/9241591013.pdf. Accessed September 23, 2012.

23 Fiore MC, Bailey WC, Cohen SF, et al. Treating tobacco use and dependence: clinical practice guideline. Rockville, MD: Department of Health and Human Services, 2000. 